\author{
Cadernos de \\ ESTUDOS LINGUIISTIICOS - (58.1), Campinas, pp. 185-192 - jan./abr. 2016
}

\title{
História sociopolítica da língua portuguesa, de Carlos Alberto Faraco (São Paulo, Parábola Editorial, 2016, 400 pp.).
}

Renhado por Marcos Bagno.

Para desmistificar a história da língua portuguesa

\author{
MARCOS BAGNO$^{1}$
}

Uma vertente surgida em data relativamente recente na historiografia da linguística é a da chamada história social das línguas. Tradicionalmente, as obras que traziam em seu título história da língua costumavam se dividir em duas narrativas distintas, a chamada história interna, um relato das mudanças ocorridas no idioma ao longo dos séculos, e a chamada história externa, que tinha em conta fatos de natureza social, histórica, política etc. que afetaram as populações falantes da língua em estudo. Essa história externa, no entanto, ocupava sempre menor espaço do que a história interna, uma opção herdeira da metodologia da linguística histórica do século XIX, essencialmente interessada nas transformações fonéticas e morfológicas detectadas numa língua, desde suas origens até o estado sincrônico da descrição. Exemplo típico dessa abordagem é a conhecida História da língua portuguesa de Paul Teyssier (publicada na França em 1980), em que os "fatos históricos" ocupam, em cada capítulo, duas ou três páginas, contra uma descrição muito mais detalhada dos "fatos linguísticos". Essa preocupação quase exclusiva com a "língua em si” atinge seu ápice com os chamados neogramáticos e exerce pesada influência nas concepções de língua que configurarão, a partir dos postulados de Saussure, que estudou com os neogramáticos, a escola de pensamento linguístico chamada estruturalismo. A grande diferença foi o abandono da perspectiva diacrônica e a concentração exclusiva na sincronia, o estado atual da língua, o que levou a uma marginalização dos estudos históricos na primeira metade do século XX.

Os desdobramentos epistemológicos que conduziram ao florescimento da chamada sociolinguística, a partir dos anos 1960, alteraram esse quadro. Os estudiosos da variação se aperceberam de que não era possível separar a língua de

\footnotetext{
${ }^{1}$ Professor da Universidade de Brasília, colaborador do Programa de Pós-Graduação em Estudos de Linguagem da Universidade Federal Fluminense na área de política linguística. E-mail: bagno. marcos@gmail.com
} 
seus falantes, o que os obrigou à consideração dos fatores de ordem sociológica para o entendimento não só da variação como também de seu correlato, a mudança linguística. O novo paradigma abandonou a chamada "ficção de homogeneidade" postulada pelo estruturalismo clássico e gerativista e passou a operar com o conceito de heterogeneidade regulada. Além da sociolinguística, outras áreas de estudo da linguagem também contribuíram para o abandono da "língua em si" e para a consideração do universo social dos falantes: antropologia linguística, etnografia da comunicação, análise do discurso, pragmática linguística, as diversas escolas reunidas sob o rótulo de funcionalismo, além das teses postuladas ainda no início do século XX por filósofos, psicólogos e linguistas soviéticos (Vygotsky, Bakhtin, Voloshinov, Jakubinskij etc.), mas que só se tornaram conhecidas e divulgadas no chamado Ocidente a partir da década de 1970.

$\mathrm{Na}$ esteira de todas essas transformações no modo de ver e de fazer linguística surgiu, sobretudo a partir da década de 1980, o interesse pela produção das histórias sociais das línguas, em que, ao contrário dos compêndios tradicionais, se dá ênfase muitíssimo maior à complexa trama de fenômenos sociais, culturais, políticos, ideológicos que configuraram ao longo do tempo as diversas comunidades linguísticas, reservando um lugar secundário aos fenômenos de natureza propriamente linguística (fonéticos, morfossintáticos, lexicais etc.) e, ainda assim, somente na medida em que fazem parte de algum fato histórico relevante. Assim foi publicada, em 1983, uma história social da língua inglesa, de autoria de Dick Leith. Em 1999, Henrique Monteagudo publicou sua história social da língua galega, com importantes contribuições para o estudo do português, que é, de fato, em perspectiva diacrônica, o galego medieval que recebeu outro nome ao ser levado cada vez mais ao sul da franja ocidental da Península Ibérica. No Brasil, cabe destacar a iniciativa pioneira de Rosa Virgínia Mattos e Silva (19402012) que reuniu e publicou, em 2004, seus Ensaios para uma sócio-história do português brasileiro. E é justamente a essa autora que vem dedicada aHistória sociopolítica da língua portuguesa, de Carlos Alberto Faraco (São Paulo, Parábola Editorial, 2016, 400 pp.).

A obra de Faraco se divide em duas grandes partes, que o autor chama de "capítulos", mais uma conclusão. O primeiro capítulo se intitula "História" e é o mais extenso. Nele o autor percorre a história da entidade sociocultural que virá a ser designada como língua portuguesa ou português, desde o final do século I a.C. - quando os romanos conquistam definitivamente o extremo noroeste da Península Ibérica, que passarão a chamar de Galécia Magna - até os dias de hoje.

Um aspecto importante na primeira parte de sua narrativa histórica é a ênfase que o autor dá à denominação da língua. As concepções políticas e culturais da Idade Média acerca da questão idiomática eram radicalmente distintas das contemporâneas, de modo que analisar a situação linguística do que viria a ser Portugal com os conceitos, muito recentes, de "nação" e "língua oficial" é arriscar-se num inevitável e enganoso anacronismo. Durante mais de mil anos após o esfacelamento do Império Romano no século $\mathrm{V}$, a única língua digna deste nome será o latim, sobretudo graças à autoridade que lhe empresta o fato de ser o idioma da Igreja romana. Reservado seu conhecimento a uma 
Cadernos de ESTUDOS LINGUISTIICOS (58.1) - jan./abr. 2016

reduzida elite de letrados, o latim é a língua da produção científica e filosófica, da teologia, dos documentos das chancelarias reais e da jurisprudência. As novas variedades linguísticas que iam surgindo graças às mudanças sofridas pelo latim imperial não têm nome próprio, são designadas como "romance" ou "vulgar" e terão de aguardar até o Renascimento para se tornarem objeto de estudo, análise, descrição e prescrição normativa. Desse modo, o romance que surgiu no noroeste da Península Ibérica, isto é, na Galiza, será chamado de "galego" (denominação que encontra seu primeiro registro por volta de 1300) e somente muito mais tarde, entre 1433-38, é que surgirá o primeiro documento em que se registra a designação "português", já para o idioma hegemônico do reino de Portugal, independente desde 1189. O termo híbrido "galego-português" é uma invenção da filologia portuguesa do século XIX e não encontra eco em nenhuma fonte documental antiga. Com a expansão marítima, iniciada no final do século XV, é que o nome "português" ou "língua portuguesa" se tornará de emprego amplo e comum. Até então, eram frequentes os usos dos termos "linguagem" ou "nossa linguagem" para designar a língua.Assim, embora seja comum encontrar em obras historiográficas a referência a uma suposta "oficialização" do português como língua da chancelaria a partir do reinado de D. Dinis (1261-1325), essa análise carece de fundamento. Faraco lembra, por exemplo, que o ensino formal continuou a ser feito em latim até o século XVIII e que, duzentos anos depois de D. Dinis, os médicos ainda redigiam suas prescrições em latim, o que chegou a suscitar um pedido formal das Cortes ao rei D. Manuel I, em 1498, para que essa prática fosse abandonada e as receitas fossem escritas em "linguagem", a que o rei aquiesceu.

A plena expansão marítima dos portugueses coincide, então, com o período em que a língua sofrerá seu processo de gramatização (com a pioneira Gramática da linguagem portuguesa, de Fernão de Oliveira, de 1536) e sua elaboração como idioma de cultura erudita e literária (Os Lusíadas, 1572). Como nova potência colonial, não fazia sentido Portugal levar para as novas terras conquistadas uma língua como o latim, imobilizada no tempo e desconhecida da grande maioria da população e sobretudo dos marinheiros e colonos enviados a explorar os territórios dominados. O mesmo fenômeno glotopolítico acompanhará as conquistas marítimas da Espanha e, mais tarde, da Inglaterra, da Holanda e da França. Sintomáticas dessa mudança de status do português diante do latim são as palavras de Fernando de Oliveira em sua gramática: "tornemos sobre nós agora que é tempo e somos senhores, porque milhor é que ensinemos a Guiné ca sejamos ensinados de Roma".

Faraco acompanha a saída da língua portuguesa da Europa e seu estabelecimento, muito lento e gradual, em terras americanas, africanas e asiáticas. Mostra algumas das consequências dessa expansão, como o surgimento de pidgins e crioulos, alguns dos quais muito relevantes até hoje (como os de Cabo Verde, da GuinéBissau e de São Tomé e Príncipe, que são as línguas hegemônicas das respectivas populações), além das diversas estratégias empregadas pelos colonizadores para contornar as complexas situações de multilinguismo em que se viram nos novos continentes alcançados. Uma das soluções encontradas foi recorrer aos chamados 
línguas, isto é, intérpretes que conheciam o português e uma ou mais línguas locais. No caso do Brasil, esses línguas podiam ser portugueses que por algum motivo (degredo, naufrágio etc.) eram obrigados a aprender a língua da comunidade em que se encontravam ou, mais tarde, índios que, criados desde pequenos nas missões religiosas, aprendiam o português e agiam como intermediários entre os europeus e as populações autóctones. Outro aspecto bem discutido na obra é a relação dos missionários religiosos com as populações locais e, por conseguinte, com suas línguas. Na América portuguesa (que era constituída de dois Estados distintos: o do Grão-Pará e Maranhão e o do Brasil), os jesuítas optaram pelo aprendizado das chamadas "línguas gerais", de base tupi (a língua geral amazônica e a língua geral paulista), para seu trabalho de conversão dos índios ao cristianismo. O jesuíta Anchieta escreveu a primeira gramática do tupi, publicada em 1595, e durante os primeiros séculos da colonização o português foi minoritário, uma vez que a maioria da população, composta de índios e mestiços, falava essas línguas gerais.

Um episódio sobre o qual a obra de Faraco se debruça com especial vagar é a publicação do chamado Diretório dos Índios, de 1757, um documento emitido por ordem do Marquês de Pombal, primeiro-ministro português, que tentava traçar uma política indigenista, com diretrizes sociais, culturais e econômicas, para o Grão-Pará e, mais adiante, para o Brasil. Expulsos os jesuítas de Portugal e de suas colônias, a Coroa tentou impor a língua portuguesa e proibir o ensino de e em qualquer outra língua em seus territórios americanos. O mérito da discussão empreendida por Faraco está em produzir uma avaliação mais realista daquilo que de fato representou a promulgação do Diretório. Avaliações apressadas e muitas vezes movidas por certo espírito romântico de idealização do passado costumam lamentar o caráter "opressor" e "autoritário" desse Diretório, responsabilizando-o quase inteiramente por um suposto desaparecimento repentino das línguas gerais no cenário cultural do Brasil, línguas que poderiam ter constituído, segundo essa visão, os primeiros elementos para a construção de uma "identidade" propriamente brasileira. Faraco, no entanto, de posse de documentação da época, demonstra que o projeto linguístico e cultural do Diretório fracassou por completo, sobretudo por ter sido traçado em gabinete, do outro lado do Atlântico, por pessoas alheias à realidade sociocultural da Amazônia. Não se deixa de falar uma língua por decreto, e o que realmente levou à diminuição do uso da língua geral amazônica não foram as malogradas tentativas de proibição oficial, mas uma série de fenômenos muito mais impactantes: a repressão à revolta da Cabanagem (1840), em que mais de 40.000 pessoas foram mortas, em sua maioria falantes da língua geral; a Guerra do Paraguai (1865-1870), porque muitos habitantes da região foram deslocados como soldados para combater longe da Amazônia e morreram longe de sua terra de origem; o ciclo da borracha, que atraiu para a região mais de meio milhão de nordestinos, todos falantes de português.

No que diz respeito à porção central da América portuguesa, um fenômeno que impulsionou o uso do português foi a descoberta de ouro nas Minas Gerais. Até esse momento (início do século XVIII), a ocupação do território brasileiro era feita de modo esparso, com focos coloniais espalhados sobretudo pelo litoral, "um mosaico de 'ilhas' coloniais, cada uma com suas peculiaridades demográficas e 
dinâmicas socioeconômicas, que mal se comunicavam entre si” (p. 139). A partir do descobrimento do ouro, esse perfil de ocupação começou a se alterar. Durante os setenta primeiros anos do século XVIII, a região das minas foi polo de atração para um enorme contingente populacional: entre 1700 e 1720, cerca de 150.000 pessoas se deslocaram de outros pontos da colônia rumo às minas, entre elas grande quantidade de escravos africanos transferidos das culturas da cana para a exploração do ouro; vieram de Portugal, entre 1701 e 1760, cerca de 600.000 pessoas também interessadas na nova riqueza econômica. $\mathrm{O}$ ouro foi assim o grande catalisador linguístico e econômico do século XVIII. Para abastecer a região mineradora foram criadas redes de comércio terrestre com São Paulo e o Sul e com a Bahia e o Nordeste. A capital da colônia se deslocou de Salvador para o Rio de Janeiro (1763), núcleo urbano mais próximo da região do ouro e porto escoador da riqueza mineral. É nessa fase que começa a se configurar a língua que virá a ser o português brasileiro e que, aos poucos, se tornará hegemônica em todo o território, empurrando para a marginalidade todas as demais línguas que compuseram durante trezentos anos uma paisagem sociocultural de intenso multilinguismo.

O reconhecimento desses processos históricos complexos é essencial para desmascarar o discurso de exaltação da pretensa "superioridade" do português sobre as demais línguas, superioridade que lhe teria garantido a vitória sobre suas eventuais "concorrentes". Esse discurso aparece, por exemplo, em texto do filólogo Serafim da Silva Neto (1917-1960), citado por Faraco (p. 142) para quem "a vitória do português não se deveu à imposição violenta da classe dominante. Ela explica-se pelo seu prestígio superior, que forçava os indivíduos ao uso da língua que exprimia a melhor forma de civilização”. Essa idealização mistificadora do português, no entanto, vem de longa data e será tratada com rigor por Faraco na segunda parte do livro.

Um ponto central da discussão empreendida na segunda metade do primeiro capítulo é a investigação da gênese da polarização sociolinguística que caracteriza o português brasileiro. Valendo-se do trabalho de diversos pesquisadores, com especial destaque para Dante Lucchesi, Faraco retraça as origens do que ele chama de clivagem sociolinguística do português brasileiro: de um lado, uma "norma culta" empregada por uma camada restrita da população, essencialmente urbana e letrada (e, por conseguinte, branca); e, do outro, uma "norma popular", empregada pela ampla maioria da população, antes rural, mas, desde a segunda metade do século XX, também urbanizada, num processo de ocupação desordenada das cidades por um enorme contingente de pessoas expulsas do campo pela concentração das terras férteis nas mãos de uma reduzida parcela de proprietários fundiários. Essa norma popular teria sua origem no contato de falantes de outras línguas (indígenas e africanas inicialmente e, mais tarde, também, línguas de imigrantes europeus) com o português, aprendido de modo irregular como segunda língua e, posteriormente, transmitido, com suas características próprias, às gerações sucessivas, já não conhecedoras das línguas ancestrais, num processo de nativização dessas variedades. Assim "nascem as variedades do português popular e, com a recusa dessas variedades pela elite, se cria a polarização sociolinguística do Brasil. Esta foi, portanto, efeito direto da profunda divisão socioeconômica característica da economia colonial 
escravocrata e da transmissão linguística irregular" (p. 148).

Essa polarização explica a ideologia linguística que caracteriza as camadas urbanas mais letradas, ideologia marcada por um profundo preconceito dirigido às variedades empregadas pela grande maioria da população, pouco letrada, pobre e predominantemente mestiça: "Se a cor da pele funcionava (e continua funcionando) como marcador social da diferença, a língua portuguesa polarizada cumpria (e continua cumprindo) essa mesma função” (p. 148). É verdade que, mais recentemente, grandes transformações sociais e econômicas reconfiguraram o perfil da população brasileira em geral (a industrialização a partir de finais do século XIX, a urbanização intensa, as movimentações de grandes segmentos populacionais entre as diferentes regiões do país, a ramificação dos meios de comunicação por todo o território, a expansão da oferta escolar etc.), de modo que se observa pouco a pouco um nivelamento sociolinguístico, com influências recíprocas da norma popular sobre a culta e vice-versa. Essa nova realidade, porém, não tem sido acompanhada por uma mudança na concepção de "língua certa" dos setores médios e altos da população, que não se dão conta das transformações ocorridas em suas próprias variedades linguísticas e continuam a cultuar um ideal linguístico irracional, sem nenhum fundamento empírico, a que o autor dá o nome de norma curta. É a essa construção da "língua imaginária" que Faraco dedica a parte final do capítulo histórico de seu livro.

O segundo capítulo, "Rumo à lusofonia", empreende, de início, uma reconstituição de um discurso mítico e mistificador (e muitas vezes, nas palavras do autor, "delirante") acerca de um suposto papel redentor e universal que a língua portuguesa estaria destinada a cumprir no mundo. Faraco reconstitui essa tradição percorrendo as obras do padre Antônio Vieira, do poeta Fernando Pessoa e do filósofo Agostinho da Silva. Cada um a seu modo (Vieira apregoando o Quinto Império; Pessoa a falar do Império da Língua Portuguesa; Agostinho da Silva a prever uma Era do Espírito Santo para a língua), esses autores contribuíram para a formação do "topos do orgulho", uma supervalorização da língua sem nenhuma base objetiva e que "só pode ser entendido como a construção imaginária compensatória do senso (cheio de ressentimento) de ser menor do que se deseja" (p. 239). A decadência de Portugal como potência internacional, iniciada muito cedo logo após suas primeiras conquistas coloniais, acelerada por sua dependência subserviente para com a Inglaterra, acentuada com a independência do Brasil em 1822 e concluída com a perda das colônias africanas a partir de 1975, deve estar na raiz dessa busca ansiosa por algo que recupere a efêmera glória do passado. Uma contribuição importante para essa mitologia veio do sociólogo brasileiro Gilberto Freyre, com sua tese do lusotropicalismo, em que se tenta conferir à colonização portuguesa um caráter diferente das demais empreitadas coloniais europeias, que foram exploradoras e violentas, ao passo que a portuguesa teria sido pacífica, uma assimilação marcada "não pela força bruta, não pelo poder militar, não pela superioridade técnica, não pela astúcia econômica, mas pelo amor, o amor fraternal", conforme escreveu o autor pernambucano em seu livro $O$ mundo que o português criou (citado por Faraco na p. 251). O lusotropicalismo quer ocultar as características verdadeiras do colonialismo português, que em nada se diferencia 
dos demais: a dominação das terras e das populações para a captura das riquezas naturais e agrícolas, o sequestro e a escravização de seres humanos, a justificação de uma suposta "missão civilizadora" com base em concepções de superioridade de uma raça sobre as demais, de uma língua sobre as demais, de uma religião sobre todas as outras, além do genocídio puro e simples.

Toda essa tradição de ocultamento da história e de mitificação do caráter do elemento colonial português - e, por conseguinte, de sua língua - deságua no conceito de lusofonia, formulado sobretudo a partir da dissolução do império português após a independência de suas colônias na África, em 1975. Faraco mostra que o tema (e o próprio termo) lusofonia tem muito mais difusão e é alvo de muito mais debate em Portugal do que no Brasil, onde raramente comparece na discussão acadêmica e, menos ainda, nos meios de comunicação de massa. Na África, a ideia de lusofonia é vista com desconfiança por povos recém-independentes, que suspeitam nela um projeto de fundo neocolonial. Em sua crítica ao projeto atual da lusofonia, Faraco o compara a outras realidades de línguas pluricêntricas que se expadiram devido ao processo colonial - o espanhol, o francês e o inglês - e demonstra as grandes discrepâncias entre elas e o português. O espanhol conta com meio bilhão de falantes nativos, distribuídos por mais de vinte países independentes, e sempre foi objeto de uma política linguística agressiva e centralizadora da parte da Espanha e de sua Real Academia, órgão máximo, até hoje, dessa política. $O$ francês e o inglês têm como principais fontes de estímulo e de financiamento países altamente desenvolvidos e industrializados, entre os mais ricos do mundo. O português, ao contrário, é língua de fato materna e hegemônica em apenas dois países - Portugal e Brasil -, uma vez que, nas demais ex-colônias, sofre a concorrência de incontáveis línguas locais e é falado por uma minoria da população. É, portanto, uma língua muito mais bipolar do que pluricêntrica. Além disso, Portugal é um país pequeno, periférico dentro do conjunto da União Europeia, sempre foi um dos mais pobres e atrasados da Europa e, ainda mais recentemente, tem se debatido com uma profunda recessão econômica. Nada disso lhe permitiria exercer o papel de centro de controle, difusão e financiamento da expansão da língua, como se dá com a França, por exemplo, onde existe um ministro de Estado da Francofonia. Por fim, com exceção do Brasil, todas as demais ex-colônias portuguesas encabeçam a listas da nações menos desenvolvidas do planeta. Tudo isso faz do projeto da lusofonia, segundo Faraco, uma quimera, sobretudo porque o discurso que ainda vigora ali é o da exaltação de valores abstratos, de "comunhão de povos", de "harmonia de culturas", um discurso herdeiro dos delírios sebastianistas e lusotropicalistas, sem fundamentos concretos e palpáveis que possam levar adiante uma verdadeira e produtiva integração dos países que têm o português como língua oficial.

Isso não elimina, no entanto, na visão do autor, a possibilidade de integração desses países, desde que se elabore um projeto realista, que procure superar as grandes desigualdades sociais, econômicas e culturais presentes em todos eles (como as altíssimas taxas de analfabetismo) e em que a gestão da língua se faça de modo coordenado e com uma participação conjunta e efetiva dos Estados que 
compõem a Comunidade de Países de Língua Portuguesa (CPLP). Para Faraco, esse projeto pode ser levado a cabo pelo IILP (Instituto Internacional da Língua Portuguesa), sediado na cidade da Praia (Cabo Verde), mas que ainda não exerce seu papel de coordenação e harmonização dessa política linguística, até mesmo pelo desinteresse demonstrado por diversos dos países, incluindo o Brasil.

A obra demonstra um aproveitamento frutífero de diversas fontes documentais, apresenta argumentos coerentes, construídos sempre a partir de dados históricos e investigações empíricas, é escrita num estilo objetivo, elegante sem afetações, de leitura acessível a não iniciados no tema, e favorece uma reflexão serena porém crítica das diversas tradições discursivas que têm sido gestadas e geridas em torno da língua portuguesa e de sua história. Contribui, primordialmente, para que se interprete essa história de um modo realista, sem arroubos nacionalistas nem saudosismos de glórias passadas. É leitura sem dúvida proveitosa não só para linguistas mas também para historiadores, antropólogos, sociólogos e todas as pessoas interessadas em conhecer mais e melhor este elemento importantíssimo na formação da sociedade brasileira que é a língua hoje majoritária da população. 